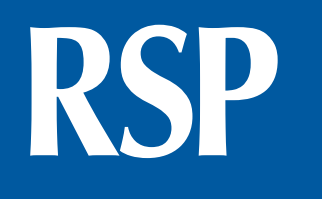

http://www.rsp.fsp.usp.br/
Revista de Saúde Pública

\title{
Cumprimento do esquema vacinal em crianças internadas por pneumonia e fatores associados
}

\author{
Amanda Tabosa Pereira da Silva',"I, Eduardo Jorge da Fonseca Lima"II', Maria de Fátima Costa \\ Caminha' ${ }^{\mathrm{IV}}$, Andresa Tabosa Pereira da Silvav, Edil de Albuquerque Rodrigues Filho ${ }^{\mathrm{VI}}$, Carmina Silva \\ dos Santos"II \\ I Instituto de Medicina Integral Prof. Fernando Figueira. Programa de Pós-Graduação em Cuidados Intensivos \\ Associados à Residência. Recife, PE, Brasil \\ " Universidade Federal de Pernambuco. Programa de Pós-Graduação em Neuropsiquiatria e Ciências do \\ Comportamento. Recife, PE, Brasil \\ III Instituto de Medicina Integral Prof. Fernando Figueira. Diretoria de Ensino. Recife, PE, Brasil \\ iv Instituto de Medicina Integral Prof. Fernando Figueira. Diretoria de Pesquisa. Recife, PE, Brasil \\ $\checkmark$ Instituto de Medicina Integral Prof. Fernando Figueira. Programa de Pós-Graduação em Educação para Ensino \\ em Saúde. Recife, PE, Brasil \\ vı Universidade Federal de Pernambuco. Programa de Pós-Graduação em Saúde da Criança e do Adolescente. \\ Recife, PE, Brasil
}

\section{RESUMO}

OBJETIVO: Verificar a adequação e os fatores associados ao cumprimento do esquema vacinal (BCG, DTP-Hib, SCR, VCP-10) em crianças internadas com pneumonia em um hospital de referência pediátrica no Nordeste do Brasil.

MÉTODOS: Estudo transversal, descritivo com componente analítico, composto por 452 crianças hospitalizadas por pneumonia no Instituto de Medicina Integral Prof. Fernando Figueira, entre 2010 e 2013. Critérios de inclusão: idade de um mês a menores de cinco anos; com comprovação do cartão vacinal. Critérios de exclusão: pneumonia hospitalar ou doença de base concomitante. Avaliamos a adequação do esquema vacinal da BCG, tetravalente, tríplice viral e pneumocócica conjugada 10 valente (VPC-10). Foram utilizados os testes qui-quadrado e exato de Fisher seguidos de regressão multivariada de Poisson, estimando-se as razões de prevalência brutas, ajustadas e os respectivos intervalos de confiança de 95\%. Participaram da análise multivariada as variáveis que na análise univariada apresentaram valor $p<0,20$.

RESULTADOS: Houve boa adequação no calendário vacinal, exceto a vacina VPC-10, que apresentou percentual inferior a $85 \%$. Observou-se associação entre o adequado cumprimento do esquema vacinal e escolaridade materna ( $89,9 \%$ ensino médio completo), sexo da criança ( $87,2 \%$ feminino), idade da criança ( $94,2 \%$ menor que seis meses) e aleitamento materno (84,3\% amamentaram).

Como citar: Silva ATP, Lima EJF, Caminha MFC, Silva ATP, Rodrigues-Filho EA, Santos CS Cumprimento do esquema vacinal em crianças internadas por pneumonia e fatores associados Rev Saude Publica. 2018;52:38.

Copyright: Este é um artigo de acesso aberto distribuído sob os termos da Licença de Atribuição Creative Commons, que permite uso irrestrito, distribuição e reprodução em qualquer meio, desde que o autor e a fonte originais sejam creditados.

CONCLUSÕES: Pela elevada taxa na escolaridade materna e pelo elevado percentual de alimentação por leite materno, pode-se entender que há uma melhor compreensão no cuidado da saúde da criança pelas genitoras estudadas nesta pesquisa, apresentando a eficácia das políticas públicas de alimentação infantil. Porém, as crianças não tiveram uma boa adequação do esquema vacinal da VPC-10, uma das principais vacinas contra a pneumonia, podendo ser esse um dos principais fatores nas causas do internamento, não apresentando influência com a classificação da gravidade da doença. Enfatiza-se dessa maneira que as causas de morbidade por pneumonia não são associadas a um único fator.

DESCRITORES: Criança. Pacientes Internados. Pneumonia, epidemiologia. Cobertura Vacinal. Programas de Imunização. 


\section{INTRODUÇÃO}

Dentre as principais doenças com impacto na mortalidade infantil no mundo, destacam-se as infecções respiratórias agudas (IRA), como a pneumonia adquirida na comunidade(PAC), responsável por aproximadamente 19\% das causas de morte no mundo ${ }^{5,14}$. A Organização Mundial de Saúde (OMS) reporta que a maior parte dos casos encontram-se nos países em desenvolvimento, e nesse contexto o Brasil está entre os 15 países com maior incidência dePAC em crianças menores de cinco anos de idade ${ }^{14,20}$. Os principais fatores de risco para a pneumonia estão agrupados em condições individuais da criança, imunização incompleta, fatores socioeconômicos, demográficos e culturais ${ }^{11}$.

Como possível impacto na pneumonia, o Programa Nacional de Imunização (PNI) no Brasil oferece atualmente no esquema vacinal infantil as vacinas de tuberculose (BCG - bacilo Calmette-Guérin), pneumocócica conjugada 10 valente(VPC-10V), tetravalente, especificamente os componentes anti-Haemophilus influenzae tipo b e anti-pertussis (DTP-Hib), e tríplice viral, componente específico do anti-sarampo (SRV) $)^{8,10,25}$.

Apesar da implantação das vacinas no calendário vacinal e da disponibilidade para a população no Sistema Único de Saúde (SUS), os dados registrados no Departamento de Informática do SUS (Datasus) em 2012, mostram que a taxa de abandono no cumprimento vacinal pelos pais ou responsáveis foi elevada, indicando que a cobertura vacinal está aquém do esperado, considerando-se o valor igual ou acima de $95 \%$ o percentual ideal de cobertura para cada vacina ${ }^{23}$.

A cobertura vacinal é um indicador de saúde que revela a quantidade de vacina dispersada pelos serviços básicos de saúde, sendo realizada pela proporção de crianças que receberam o esquema completo de vacinação em relação ao número de crianças existentes na população da mesma faixa etária avaliada. O esquema completo é caracterizado pela aplicação das vacinas preconizadas pelo PNI, cujas doses foram aplicadas nas idades indicadas (adequação epidemiológica) e com o aprazamento correto (adequação imunológica) ${ }^{2}$.

Se as crianças não forem vacinadas ficarão mais suscetíveis à contração de doenças, sendo a pneumonia um exemplo, devido a elevada taxa de incidência ${ }^{6,17}$. As justificativas tradicionalmente utilizadas pelos responsáveis das crianças para não completar o esquema vacinal são: sem caderneta de vacinação; falta de tempo; dificuldade de ir ao posto de vacinação (acesso); recusa da vacinação; "posto estava fechado", falta de vacina nos serviços; contraindicação médica; evento adverso em dose anterior, entre outros motivos ${ }^{12,17}$.

Pela importância epidemiológica das pneumonias e sua letalidade, tornam-se necessários estudos voltados para a sua prevenção. Este estudo verificou a adequação e os fatores associados ao cumprimento do esquema vacinal (BCG, DTP-Hib, SCR, VCP-10) em crianças internadas com pneumonia em um hospital de referência em pediatria no Nordeste do Brasil.

\section{MÉTODOS}

Foi realizado um estudo transversal, descritivo com componente analítico, composto por 452 crianças hospitalizadas por pneumonia comunitária no Instituto de Medicina Integral Professor Fernando Figueira (IMIP). O período da coleta foi de outubro de 2010 a setembro de 2013. O IMIP caracteriza-se por ser um hospital de referência em pediatria, responsável, em Pernambuco, pelo internamento de cerca de $30 \%$ dos casos de pneumonia em menores de cinco anos, segundo dados obtidos no Datasus em 2012.

Os critérios de inclusão foram crianças internadas no IMIP com pneumonia comunitária, com idade entre um mês e cinco anos, e que apresentavam comprovação do calendário vacinal. Foram excluídas crianças com pneumonia hospitalar ou portadoras de doenças de base concomitante como: cardiopatias, pneumopatias crônicas, nefropatias, neuropatias, hemoglobinopatias, hepatopatias, imunodeficiência, fibrose cística e malformações congênitas pulmonares. O recrutamento dos pacientes foi realizado na emergência ou serviço de pronto atendimento pediátrico, nas enfermarias ou na unidade de terapia intensiva pediátrica da instituição. 
O diagnóstico de pneumonia foi baseado nos critérios clínicos e radiológicos estabelecidos pela OMS, incluindo a classificação de gravidade, para estudos epidemiológicos de efetividade vacinal $^{13,22}$. As variáveis foram classificadas em quatro grupos: dados sociodemográficas materna (idade materna; ensino médio completo; trabalho materno; renda familiar; aglomeração domiciliar e tabagismo na residência); dados biológicos da criança (idade em meses; sexo; peso ao nascer; prematuridade; aleitamento materno); dados da classificação da pneumonia (pneumonia; pneumonia grave e pneumonia muito grave) e dados de adequação da vacina (BCG; DTP-Hib; SRV e VPC-10V).

A classificação de adequação para cada vacina ocorreu de acordo com a idade da criança, que variou de um a 59 meses, e o esquema preconizado no Calendário Básico de Vacinação da Criança recomendado pelo Ministério da Saúde entre 2006 e 2013. Assim, considerou-se como adequado os casos em que a caderneta da criança apresentava comprovação de dose aplicada na idade indicada e com o aprazamento adequado (Quadro).

Quadro. Definição das vacinas investigadas em crianças hospitalizadas com pneumonia no Instituto de Medicina Integral Prof. Fernando Figueira. Pernambuco, Brasil, outubro/2010 a setembro/2013.

\begin{tabular}{|c|c|c|c|}
\hline Vacina & Descrição & Aprazamento & Adequação \\
\hline BCG & $\begin{array}{c}\text { A vacina da BCG é realizada ao nascer, } \\
\text { nas maternidades de grande porte no } \\
\text { Brasil desde } 1991^{\mathrm{a}} \text {. }\end{array}$ & Ao nascer, realizar uma única dose & $\begin{array}{l}\text { Foi considerado adequado para as crianças com } \\
\text { comprovação de uma dose }\end{array}$ \\
\hline $\begin{array}{l}\text { Tetravalente } \\
\text { (DTP-Hib) }\end{array}$ & $\begin{array}{l}\text { No ano de 2002, foi implantada a vacina } \\
\text { conjugada tetravalente (difteria, tétano, } \\
\text { pertussis e Haemophilus influenzae tipo } \\
\text { b - conjugada). No ano de 2013, foi } \\
\text { acrescentado mais um componente, } \\
\text { tornando-se pentavalente (difteria, tétano, } \\
\text { pertussis, hepatite B e Haemophilus } \\
\text { influenzae tipo b - conjugada) }{ }^{\mathrm{a}, \mathrm{b}} \text {. }\end{array}$ & $\begin{array}{l}\text { O aprazamento desta vacina } \\
\text { permaneceu o mesmo, independente } \\
\text { do acréscimo do componente da } \\
\text { hepatite } B \text {. } \\
1^{\circ} \text { dose }-2 \text { meses } \\
2^{\circ} \text { dose }-4 \text { meses } \\
3^{\circ} \text { dose }-6 \text { meses }\end{array}$ & $\begin{array}{l}\text { Foi considerado adequado as crianças que } \\
\text { estavam de acordo com a quantidade de doses } \\
\text { estabelecida pelo MS pela respectiva idade em } \\
\text { meses: } \\
\qquad \begin{array}{c}1 \mathrm{a}<2 \text { meses: zero dose } \\
2 \mathrm{a}<4 \text { meses: } 1 \text { dose } \\
4 \mathrm{a}<6 \text { meses: } 2 \text { doses } \\
6 \mathrm{a}<60 \text { meses: } 3 \text { doses }\end{array}\end{array}$ \\
\hline $\begin{array}{l}\text { Tríplice viral } \\
\text { (SRV) }\end{array}$ & $\begin{array}{l}\text { No ano de 2003, houve a implantação } \\
\text { da vacina conjugada tríplice viral } \\
\text { (sarampo, caxumba e rubéola). Já no } \\
\text { ano de 2013, foi acrescentado mais um } \\
\text { componente, denominando-se então } \\
\text { tetraviral (sarampo, caxumba, rubéola e } \\
\text { varicela-atenuada) })^{a, c} \text {. }\end{array}$ & $\begin{array}{l}\text { Houve mudança no aprazamento da } \\
\text { vacina, sendo: } \\
\text { Em } 2003 \text { - Tetraviral: } \\
1 \text { dose a partir dos } 12 \text { meses. } \\
\text { Em } 2013 \text { - Tetraviral: } \\
1^{\circ} \text { dose }-12 \text { meses } \\
\text { Tríplice viral: } \\
2^{\circ} \text { dose: a partir dos } 15 \text { meses }\end{array}$ & $\begin{array}{c}\text { Foi considerado adequado as crianças que } \\
\text { estavam de acordo com a quantidade de doses } \\
\text { estabelecida pelo MS pela respectiva idade em } \\
\text { meses: } \\
\text { Antes de } 2013 \text { : } \\
\text { Crianças }>12 \text { meses devem apresentar } 1 \text { única } \\
\text { dose da tríplice viral } \\
\text { A partir de } 2013 \text { : } \\
\text { Crianças }>15 \text { meses devem apresentar } 2 \text { doses, } \\
\text { sendo a } 1^{\circ} \text { tríplice viral e a } 2^{\circ} \text { tetra viral }\end{array}$ \\
\hline $\begin{array}{l}\text { Pneumocócica } \\
\text { conjugada } 10 \\
\text { valente (VPC-10) }\end{array}$ & $\begin{array}{l}\text { Em 2010, foi implantada a VPC-10, } \\
\text { que demandando quatro esquemas } \\
\text { diferentes }{ }^{\text {a,d }} \text {. Em } 2016 \text {, houve mudança } \\
\text { no aprazamento dessa vacina, sendo } \\
\text { realizada aos } 2 \text { e } 4 \text { meses }\left(1^{\circ} \text { e } 2^{\circ} \text { dose, }\right. \\
\text { respectivamente) e reforço aos } 12 \text { meses. } \\
\text { Porém, esse novo aprazamento não } \\
\text { interfere na análise dessa pesquisa, visto } \\
\text { que essa modificação foi realizada depois } \\
\text { da coleta dos dados. }\end{array}$ & $\begin{array}{c}\text { No primeiro ano de implantação } \\
\text { dessa vacina, o MS estipulou } \\
4 \text { diferentes tipos de esquema } \\
\text { vacinal, determinados pela idade da } \\
\text { criança, sendo }{ }^{\text {a,d: }} \text {. } \\
2 \text { a } 6 \text { meses: } 3 \text { doses e } 1 \text { reforço } \\
7 \text { a } 11 \text { meses: } 2 \text { doses e } 1 \text { reforço } \\
10 \text { a } 13 \text { meses: } 2 \text { doses e sem reforço } \\
12 \text { a }<24 \text { meses: } 1 \text { dose e sem } \\
\text { reforço }\end{array}$ & $\begin{array}{c}\text { Foi considerado adequado as crianças que } \\
\text { estavam de acordo com a quantidade de doses } \\
\text { e reforço estabelecido pelo MS pela respectiva } \\
\text { idade em meses: } \\
\text { No ano de } 2010 \text { : } \\
2 \text { a } 6 \text { meses: } 4 \text { aplicações } \\
7 \text { a } 11 \text { meses: } 3 \text { aplicações } \\
10 \text { a } 13 \text { meses: } 2 \text { aplicações } \\
12 \text { a }<24 \text { meses: } 1 \text { aplicação } \\
\text { A partir de } 2011 \text { : } \\
<2 \text { meses: a dose } \\
2 \text { a }<4 \text { meses: } 1 \text { dose } \\
4 \text { a }<6 \text { meses: } 2 \text { doses } \\
6 \text { a }<12 \text { meses } 3 \text { doses } \\
>12 \text { meses: } 3 \text { doses e } 1 \text { reforço }\end{array}$ \\
\hline
\end{tabular}

MS: Ministério da Saúde

a Ministério da Saúde (BR), Secretaria de Vigilância em Saúde, Departamento de Vigilância Epidemiológica. Programa Nacional de Imunizações (PNI): 40 anos. Brasília (DF); 2013 [citado 17 jul 2017]. Disponível em: http://bvsms.saude.gov.br/bvs/publicacoes/programa_nacional_imunizacoes_pni40.pdf

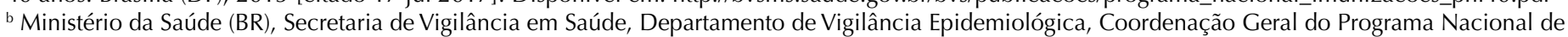
Imunizações. Informe técnico da introdução da vacina pentavalente: vacina adsorvida difteria, tétano, pertussis, hepatite B (recombinante) e Haemophilus influenzae tipo b (conjugada). Brasília (DF); 2012 [citado 14 jul 2017]. Disponível em: http://www.sgc.goias.gov.br/upload/arquivos/2012-06/informetecnico-vacina-pentavalente.pdf

c Ministério da Saúde (BR), Secretaria de Vigilância em Saúde, Departamento de Vigilância Epidemiológica, Coordenação Geral do Programa Nacional de Imunizações. Informe técnico de introdução da vacina tetra viral: vacina sarampo, caxumba, rubéola e varicela (atenuada). Brasília (DF); 2013 [citado 17 jul 2017]. Disponível em: http://www.sopape.com.br/data/conteudo/arquivos/informe_tecnico_introducao_vacina_tetraviral.pdf

d Ministério da Saúde (BR), Secretaria de Vigilância em Saúde, Departamento de Vigilância Epidemiológica, Coordenação Geral do Programa Nacional de Imunizações. Informe técnico da vacina pneumocócica 10-valente (conjugada). Brasília (DF); 2010 [citado fev 2010]. Disponível em: http://www.sgc. goias.gov.br/upload/links/arq_723_infotec.pdf 
Os dados foram digitados no Excel 2007 em duplicata, validados no EpiInfo 3.5.2 e analisados no programa Stata 12.1. A análise dos fatores associados ao calendário vacinal adequado para as vacinas BCG, DTP-Hib, SRV e VPC-10V, em função de variáveis sociodemográficas maternas e biológicas de crianças foi realizada através da regressão multivariada de Poisson, estimando-se as razões de prevalência (RP) brutas, ajustadas e os respectivos intervalos de confiança de 95\%. Participaram da análise multivariada as variáveis que na análise univariada apresentaram valor $\mathrm{p}<20 \%$. Para analisar a distribuição de frequência e associação dos dias de internamento, internamento em UTI e evolução para alta ou óbito em função do esquema vacinal adequado para as vacinas estudadas foram utilizados os testes qui-quadrado e o Exato de Fisher, quando necessário. Para todos os testes considerou-se o nível de significância $<5 \%$. As vacinas estudadas (BCG, DTP-Hib, SCR e VPC-10) foram consideradas variáveis independentes, as demais variáveis dependentes.

Este estudo teve aprovação no Comitê de Ética em Pesquisa do Instituto de Medicina Integral Prof. Fernando Figueira, CAAE 30928314.9.0000.5201, sob Protocolo 4196-14 aprovado em 11 de junho de 2014, de acordo com a Resolução 466/12 do Conselho Nacional de Saúde do Ministério da Saúde do Brasil referente a pesquisas com seres humanos.

\section{RESULTADOS}

Foram estudadas 452 crianças internadas com pneumonia no período de outubro de 2010 a setembro de 2013, sendo que a média de idade das crianças foi de 17,5 e a mediana de 14 meses. Nas Tabelas 1, 2 e 3 estão descritas a distribuição das frequências de acordo com a adequação vacinal, segundo as variáveis sociodemográficas, biológicas, classificação da pneumonia, tempo de internamento hospitalar e unidade de terapia intensiva e evolução.

Na Figura é apresentado o cumprimento das vacinas BCG, tetravalente, tríplice viral e VPC-10. Esta última apresentou o menor percentual na adequação do cumprimento vacinal, sendo inferior a 85\%; as outras vacinas apresentaram um percentual de adequação superior a 97\%.

Na Tabela 1 observa-se a análise entre o cumprimento do calendário vacinal e as variáveis sociodemográficas maternas e biológicas de crianças internadas com pneumonia no IMIP. Em relação às variáveis verificadas na análise bivariada, destaca-se que o ensino médio completo, a renda familiar maior que um salário mínimo, o sexo feminino, a idade das crianças e o recebimento do leite materno apresentaram associação estatisticamente significante com o cumprimento do calendário vacinal. Para avaliar o efeito independente de cada uma dessas variáveis foi ajustado o modelo de regressão de Poisson multivariado, em que apenas a escolaridade materna, o sexo feminino, a idade das crianças e o recebimento do leite materno permaneceram significantes.

Na Tabela 2 encontra-se a distribuição de frequência e associação da classificação da pneumonia em função do esquema vacinal adequado para as vacinas BCG, tetravalente, tríplice viral e VPC-10 de crianças internadas com pneumonia no IMIP. Não foi observada diferença estatisticamente significante.

Na Tabela 3 verifica-se a distribuição de frequência do cumprimento do esquema vacinal de acordo com a duração do internamento, indicação de UTI e desfecho final de crianças internadas com pneumonia no IMIP. Também não foi observada associação entre essas variáveis e o cumprimento do esquema vacinal.

\section{DISCUSSÃO}

As pneumonias constituem importante causa de mortalidade em todo o mundo e no Brasil, por isso o global action plan for prevention and control of pneumonia (GAPP) ressalta 
Tabela 1. Adequação do calendário vacinal, segundo variáveis sociodemográficas maternas e biológicas de crianças internadas com pneumonia no Instituto de Medicina Integral Prof. Fernando Figueira. Pernambuco, Brasil, outubro/2010 a setembro/2013.

\begin{tabular}{|c|c|c|c|c|c|c|}
\hline \multirow{2}{*}{ Especificação dos } & \multicolumn{6}{|c|}{ Calendário vacinal adequado } \\
\hline & $\begin{array}{l}\text { Amostra } \\
\mathrm{n}=4^{2} 2^{\mathrm{a}}\end{array}$ & n (\%) & $\begin{array}{l}\text { RP bruta } \\
\text { (IC95\%) }\end{array}$ & $\mathbf{p}^{\mathbf{b}}$ & $\begin{array}{l}\text { RP ajustada } \\
\text { (IC95\%) }\end{array}$ & $\mathbf{p}^{\mathbf{b}}$ \\
\hline \multicolumn{7}{|c|}{ Sociodemográficas maternas } \\
\hline Idade (anos) & & & & 0,273 & & \\
\hline$<20$ e 36 ou mais & 105 & $83(79,0)$ & 1 & & & \\
\hline 20 a 35 & 344 & $289(84,0)$ & $1,06(0,95-1,18)$ & & & \\
\hline Ensino médio completo & & & & 0,001 & & 0,001 \\
\hline Sim & 168 & $151(89,8)$ & $1,14(1,05-1,23)$ & & $1,15(1,06-1,25)$ & \\
\hline Não & 270 & $213(78,8)$ & 1 & & 1 & \\
\hline Trabalho materno & & & & 0,669 & & \\
\hline Sim & 119 & $97(81,5)$ & 1 & & & \\
\hline Não & 329 & $274(83,2)$ & $1,02(0,92-1,12)$ & & & \\
\hline Renda familiar (SM) & & & & 0,004 & & 0,137 \\
\hline$\leq 1$ & 275 & $217(78,9)$ & 1 & & 1 & \\
\hline$>1$ & 177 & $157(88,7)$ & $1,12(1,04-1,22)$ & & $1,07(0,98-1,17)$ & \\
\hline Aglomeração & & & & 0,279 & & \\
\hline Sim & 118 & $93(78,8)$ & 1 & & & \\
\hline Não & 322 & $269(83,5)$ & $1,06(0,95-1,18)$ & & & \\
\hline Tabagismo na residência & & & & 0,085 & & 0,240 \\
\hline Sim & 139 & $108(77,7)$ & 1 & & 1 & \\
\hline Não & 311 & $264(84,8)$ & $1,09(0,99-1,21)$ & & $1,06(0,96-1,17)$ & \\
\hline \multicolumn{7}{|c|}{ Biológicas das crianças } \\
\hline Sexo & & & & 0,016 & & 0,002 \\
\hline Masculino & 234 & $184(78,6)$ & 1 & & 1 & \\
\hline Feminino & 218 & $190(87,1)$ & $1,11(1,02-1,20)$ & & $1,13(1,05-1,23)$ & \\
\hline Peso ao nascer (g) & & & & 0,273 & & \\
\hline$<2.500$ & 47 & $36(76,6)$ & 1 & & & \\
\hline$\geq 2.500$ & 368 & $309(83,9)$ & $1,10(0,93-1,29)$ & & & \\
\hline Prematuridade & & & & 0,404 & & \\
\hline Sim & 36 & $28(77,7)$ & 1 & & & \\
\hline Não & 387 & $325(83,9)$ & $1,08(0,90-1,29)$ & & & \\
\hline Idade & & & & $<0,001$ & & $<0,001$ \\
\hline$<6$ meses & 119 & $112(94,1)$ & $1,31(1,16-1,47)$ & & $1,35(1,20-1,53)$ & \\
\hline 6 a 12 meses & 85 & $72(84,7)$ & $1,18(1,02-1,36)$ & & $1,21(1,05-1,39)$ & \\
\hline 13 a 24 meses & 120 & $98(81,6)$ & $1,14(0,99-1,30)$ & & $1,15(1,01-1,32)$ & \\
\hline$>24$ meses & 128 & $92(71,8)$ & 1 & & 1 & \\
\hline Aleitamento materno & & & & 0,031 & & 0,029 \\
\hline Sim & 414 & $349(84,3)$ & $1,35(1,03-1,77)$ & & $1,32(1,03-1,68)$ & \\
\hline Não & 32 & $20(62,5)$ & 1 & & 1 & \\
\hline
\end{tabular}

SM: salário mínimo

a A amostra variou devido à ausência de informação.

b Poisson.

a importância das vacinas como fator de proteção para a saúde das crianças. Reforça, dessa maneira, que o uso das vacinas BCG, combinadas com componentes pertusis e Hib, tríplice viral e VPC-10 está relacionado com a redução da incidência da doença ${ }^{1,9,24}$.

Neste estudo, observamos elevado percentual de adequação para as vacinas BCG, tetravalente e tríplice viral; no entanto, para a VPC-10, o percentual de adequação mostrou-se inferior ao recomendado pelo Ministério da Saúde ${ }^{23}$. Apesar da amostra ter analisado as cadernetas de vacinas de crianças hospitalizadas, os resultados de cobertura mostraram-se semelhantes aos encontrados em outras populações de crianças no Brasil ${ }^{15}$. 
Tabela 2. Distribuição de frequência do cumprimento do esquema para as vacinas BCG, Tetravalente, Tríplice viral e VPC-10 de acordo com a classificação da pneumonia em crianças internadas com pneumonia no Instituto de Medicina Integral Prof. Fernando Figueira. Pernambuco, Brasil, outubro/2010 a setembro/2013. $\left(\mathrm{n}=452^{\mathrm{a}}\right)$

\begin{tabular}{|c|c|c|c|c|c|}
\hline \multirow{3}{*}{ Adequação da vacina } & \multicolumn{4}{|c|}{ Classificação da pneumonia } & \multirow{3}{*}{$\mathbf{p}^{\mathbf{b}}$} \\
\hline & Pneumonia & Grave & Muito grave & Total & \\
\hline & n (\%) & n (\%) & n $(\%)$ & n (\%) & \\
\hline BCG & & & & & 0,146 \\
\hline Sim & $73(16,3)$ & $364(81,4)$ & $10(2,2)$ & $447(100)$ & \\
\hline Não & $0(0)$ & $4(80,0)$ & $1(20,0)$ & $5(100)$ & \\
\hline Tetravalente & & & & & 0,305 \\
\hline Sim & $73(16,6)$ & $355(80,9)$ & $11(2,5)$ & $439(100)$ & \\
\hline Não & $0(0)$ & $13(100)$ & $0(0)$ & $13(100)$ & \\
\hline Tríplice viral & & & & & 1,000 \\
\hline Sim & $72(16,1)$ & $363(81,4)$ & $11(2,5)$ & $446(100)$ & \\
\hline Não & $1(16,7)$ & $5(83,3)$ & $0(0)$ & $6(100)$ & \\
\hline Pneumocócica $^{a}$ & & & & & 0,218 \\
\hline Sim & $62(16,8)$ & $297(80,3)$ & $11(3,0)$ & $370(100)$ & \\
\hline Não & $8(11,59)$ & $61(88,4)$ & $0(0)$ & 69 (100) & \\
\hline
\end{tabular}

BCG: Bacilo Calmette-Guérin; VPC-10: Vacina pneumocócica conjugada 10 valente

a A amostra variou por analisar apenas as crianças com idade compatível ao período de implantação da vacina $(\mathrm{n}=439)$.

b Testes qui-quadrado e exato de Fisher.

O percentual de adequação observado para a vacina BCG, tetravalente e tríplice viral pode ser explicado pelo tempo de implantação desses imunobiológicos no calendário vacinal brasileiro. Haja vista a BCG estar disponível desde a primeira implantação da caderneta de vacinação pelo Ministério da Saúde (MS) em 1973, da mesma forma que a monovalente contra o sarampo ${ }^{a}$. As vacinas conjugadas tetravalente e tríplice viral foram introduzidas no calendário nos anos de 2002 e 2003, respectivamente.

Por outro lado, o tempo de implantação da VPC-10 no calendário de vacinação é inferior ao das vacinas referidas anteriormente. Dessa forma, pode-se conjecturar a menor frequência no percentual da cobertura vacinal encontrada. Essa informação corrobora outros estudos, os quais atribuem a recente implantação da vacina pneumocócica no SUS com a baixa adesão ao cumprimento do esquema ${ }^{12, a}$.

Quanto à associação do cumprimento do esquema vacinal com as variáveis maternas estudadas, observou-se uma diferença estatisticamente significante entre o cumprimento do calendário e a idade materna, em que a adequação foi maior nas crianças de mães que possuíam o ensino médio completo. Estudos enfatizam a relação entre a baixa escolaridade materna com o não cumprimento do esquema vacinal, principalmente em países em desenvolvimento. Assim, a mulher que apresente um maior nível de escolaridade tem maiores possibilidades de acesso à informação sobre saúde e prevenção de doenças e proporciona um melhor cuidado à criança ${ }^{1,19}$.

a Ministério da Saúde (BR), Secretaria de Vigilância em Saúde, Departamento de Vigilância Epidemiológica, Coordenação Geral do Programa Nacional de Imunizações. Informe técnico da introdução da vacina pentavalente: vacina adsorvida difteria, tétano, pertussis, hepatite B (recombinante) e Haemophilus influenzae tipo b (conjugada). Brasília (DF); 2012 [citado 14 jul 2017]. Disponível em: http:// www.sgc.goias.gov.br/upload/ arquivos/2012-06/informetecnico-vacina-pentavalente.pdf
No que concerne a idade materna, embora esta variável não tenha se apresentado estatisticamente significante em relação ao cumprimento do esquema vacinal, percebeu-se que um maior percentual foi observado entre as crianças de mães com idade entre 20 a 35 anos com adequação do calendário com esquema vacinal para a idade. Estudos mostram que os cuidados direcionados às crianças como cumprimento do esquema vacinal, alimentação, higiene, educação e saúde estão normalmente atrelados a alguns fatores como: idade materna entre 20 e 35 anos, escolaridade materna superior ou igual a oito anos de estudo e a renda familiar maior que um salário mínimo. Desta forma, espera-se que famílias que apresentam essas características tenham maior cuidado com a saúde da criança, o que foi confirmado no estudo em questão ${ }^{1,4,20}$.

Ainda de acordo com as variáveis socioeconômicas, quanto a renda familiar, mais da metade das crianças residia com famílias que possuíam renda inferior a um salário mínimo, resultado característico de países em desenvolvimento ${ }^{3,19}$; embora, neste estudo, isto não tenha apresentado 
Tabela 3. Distribuição de frequência do cumprimento do esquema das vacinas BCG, Tetravalente, Tríplice viral e VPC-10 de acordo com o total de dias de internamento, internamento em UTI e evolução para alta ou óbito em crianças internadas com pneumonia no Instituto de Medicina Integral Prof. Fernando Figueira. Pernambuco, Brasil, outubro/2010 a setembro/2013. $\left(\mathrm{n}=452^{\mathrm{a}}\right)$

\begin{tabular}{|c|c|c|c|c|}
\hline \multirow{3}{*}{ Adequação da vacina } & \multicolumn{2}{|c|}{ Tempo de internamento hospitalar } & \multirow{3}{*}{\begin{tabular}{|l|} 
Total \\
n (\%)
\end{tabular}} & \multirow{3}{*}{$\mathbf{p}^{\mathbf{b}}$} \\
\hline & $\leq 7$ dias & $>7$ dias & & \\
\hline & n (\%) & n (\%) & & \\
\hline BCG & & & & 0,212 \\
\hline Sim & $227(50,9)$ & $219(49,1)$ & $446(100)$ & \\
\hline Não & $1(20,0)$ & $4(80,0)$ & $5(100)$ & \\
\hline Tetravalente & & & & 0,576 \\
\hline Sim & $220(50,2)$ & $218(49,7)$ & $438(100)$ & \\
\hline Não & $8(61,5)$ & $5(38,4)$ & $13(100)$ & \\
\hline Tríplice viral & & & & 1,000 \\
\hline $\operatorname{Sim}$ & $225(50,5)$ & $220(49,4)$ & $445(100)$ & \\
\hline Não & $3(50,0)$ & $3(50,0)$ & $6(100)$ & \\
\hline Pneumocócica ${ }^{a}$ & & & & 0,795 \\
\hline Sim & $186(50,4)$ & $183(49,5)$ & $369(100)$ & \\
\hline \multirow[t]{3}{*}{ Não } & $36(52,1)$ & $33(47,8)$ & $69(100)$ & \\
\hline & \multicolumn{2}{|c|}{ Internamento em UTI } & & \\
\hline & Sim & Não & & \\
\hline BCG & & & & 1,000 \\
\hline $\operatorname{Sim}$ & $17(3,8)$ & $430(96,2)$ & $447(100)$ & \\
\hline Não & $0(0)$ & $5(100)$ & $5(100)$ & \\
\hline Tetravalente & & & & 1,000 \\
\hline Sim & $17(3,9)$ & $422(96,1)$ & $439(100)$ & \\
\hline Não & $0(0)$ & $13(100)$ & $13(100)$ & \\
\hline Tríplice viral & & & & 1,000 \\
\hline $\operatorname{Sim}$ & $17(3,8)$ & $429(96,2)$ & $446(100)$ & \\
\hline Não & $0(0)$ & $6(100)$ & $6(100)$ & \\
\hline Pneumocócicaa & & & & 0,218 \\
\hline Sim & $15(4,1)$ & $355(95,9)$ & $370(100)$ & \\
\hline \multirow[t]{3}{*}{ Não } & $1(1,4)$ & $68(98,5)$ & $69(100)$ & \\
\hline & \multicolumn{2}{|c|}{ Evolução } & & \\
\hline & Alta & Óbito & & \\
\hline BCG & & & & 1,000 \\
\hline $\operatorname{Sim}$ & $440(98,4)$ & $7(1,6)$ & 447 (100) & \\
\hline Não & $5(100)$ & $0(0)$ & $5(100)$ & \\
\hline Tetravalente & & & & 1,000 \\
\hline Sim & $432(98,4)$ & $7(1,6)$ & $439(100)$ & \\
\hline Não & $13(100)$ & $0(0)$ & $13(100)$ & \\
\hline Tríplice viral & & & & 1,000 \\
\hline $\operatorname{Sim}$ & $439(98,4)$ & $7(1,6)$ & $446(100)$ & \\
\hline Não & $6(100)$ & $0(0)$ & $6(100)$ & \\
\hline Pneumocócica & & & & 0,603 \\
\hline $\operatorname{Sim}$ & $363(98,1)$ & $7(1,9)$ & $370(100)$ & \\
\hline Não & 69 (100) & $0(0)$ & 69 (100) & \\
\hline
\end{tabular}

BCG: Bacilo Calmette-Guérin; VPC-10: Vacina pneumocócica conjugada 10 valente; UTI: unidade de terapia intensiva ${ }^{a}$ A amostra variou por analisar apenas as crianças com idade compatível ao período de implantação da vacina $(n=439)$.

${ }^{\mathrm{b}}$ Testes qui-quadrado e exato de Fisher.

associação com o cumprimento do esquema vacinal nas crianças avaliadas Contudo, evidências mostram que as famílias com contexto socioeconômico desfavorecido apresentam risco de 2,4vezes a mais de internação hospitalar, enfatizando que o nível socioeconômico da população influencia no cuidado com a saúde, uma vez que o acesso e a busca a informação são mais restrita ${ }^{3,19}$. 


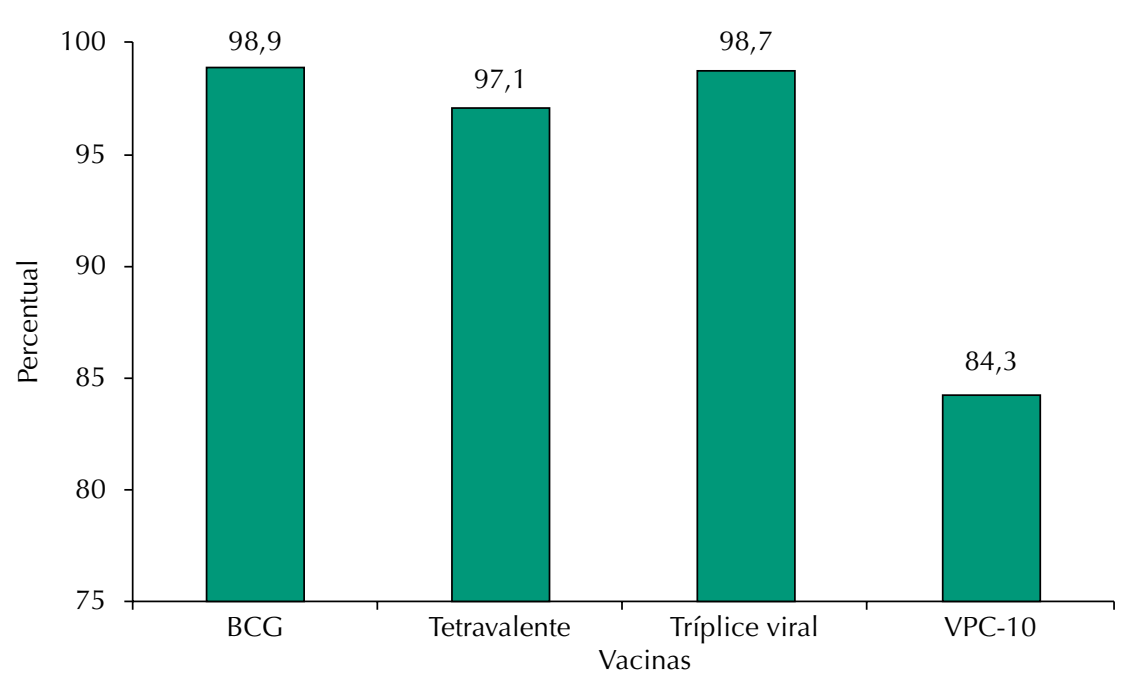

BCG: Bacilo Calmette-Guérin; VPC-10: Vacina pneumocócica conjugada 10 valente

Figura. Distribuição de frequência da adequação do cumprimento do esquema vacinal de acordo com as vacinas específicas das crianças internadas com pneumonia no Instituto de Medicina Integral Prof. Fernando Figueira. Pernambuco, Brasil, outubro/2010 a setembro/2013.

Com relação às variáveis biológicas da criança, houve associação entre o sexo e o cumprimento do esquema vacinal, o qual foi observado um maior percentual na cobertura vacinal para as meninas, apesar da população estudada ser predominante do sexo masculino. O sexo da criança como fator de risco para a pneumonia não está completamente esclarecido, não havendo ainda um consenso na literatura ${ }^{5,18}$. Sabe-se que o sexo masculino está mais suscetível a infecções respiratórias baixas e que o sexo feminino tem maior resistência a infecções, sendo explicada pela melhor resposta da imunidade em meninas ${ }^{5,18}$.

De acordo com a idade da criança houve associação com o cumprimento do esquema vacinal, em que ocorreu um decréscimo do percentual de adequação do calendário à medida em que a faixa etária aumentava. Isso pode ser conjecturado considerando que o calendário de acompanhamento do desenvolvimento infantil tem maior número de consultas no primeiro ano de vida, sobretudo no primeiro semestre, o que possibilita maior acesso aos serviços de saúde e, consequentemente, maior adesão ao cumprimento do esquema vacinal ${ }^{16}$.

Foi observada ainda associação entre a adequação do calendário em relação ao aleitamento materno, uma vez que o percentual de adequação foi maior entre as crianças que receberam leite materno. Isso pode ser explicado pelo fato de que durante os primeiros meses de vida a criança esteja recebendo aleitamento materno; a recomendação do MS é que recebam aleitamento materno por dois anos. A prática exclusiva é por seis meses de vida, período em que todos os esforços dos serviços das políticas públicas de saúde estão focados. As evidências científicas afirmam que a associação entre o aleitamento materno com o cumprimento do esquema vacinal reforça a proteção contra doenças em crianças ${ }^{4,21,24}$.

Além disso, as crianças que não são amamentadas têm o risco 61 vezes mais de estarem suscetíveis a internações por pneumonia, quando comparadas às crianças que foram amamentadas exclusivamente por seis meses de vida ${ }^{24}$. Um estudo realizado na Suécia indica que as crianças com amamentação exclusiva de 90 dias ou mais e que foram vacinadas com a Hib e a pneumocócica, concomitantemente, obtiveram uma melhor proteção sorológica quando comparadas com as crianças que foram amamentadas por poucos dias ${ }^{21}$. Desta forma, corroboram que a importância da realização concomitante destas práticas, amamentação exclusiva por seis meses e o cumprimento do esquema vacinal, poderão conferir uma maior proteção às crianças nesta faixa etária ${ }^{7,21}$.

No que se refere à classificação da pneumonia, período de internamento e indicação de UTI das crianças internadas, não houve associação com o cumprimento do esquema vacinal, 
embora grande parte das crianças apresentassem adequação do calendário. Ainda neste estudo, mesmo tendo sido observada a associação entre o cumprimento do esquema vacinal e outras variáveis como, a escolaridade materna, sexo, idade da criança e aleitamento materno, entende-se que o processo saúde-doença esteja atrelado a uma série de eventos multifatoriais e não exclusivamente a adequação do esquema vacinal entende-se que o processo saúde-doença está atrelado a uma serie de eventos multifatoriais e não exclusivamente a adequação do esquema vacinal. Contudo, a VPC-10 é um fator importante e específico para a proteção contra a pneumonia, tendo como consequência a diminuição da vulnerabilidade e a promoção à saúde da população, sobretudo de crianças.

O fato de o estudo ter se proposto apenas a verificar o cumprimento do calendário vacinal não possibilitou a definição do status imunológico da criança após a vacinação, o que apresentou uma limitação no estudo. As crianças que apresentaram pneumonia, independente da classificação, poderiam até mesmo ter apresentado um esquema atualizado, porém não concluído, o que as deixariam ainda em situação de vulnerabilidade. Da mesma forma, as crianças que passaram mais dias internadas ou que precisaram de internamento em UTI, também não tiveram a situação sorológica verificada em relação às vacinas recebidas.

Para as políticas públicas este estudo apresenta, de forma geral, eficiência e eficácia na alimentação infantil e no investimento de campanhas vacinais, visto que houve um quadro de adequação para estes principais destaques. Apesar dos dados avaliados, faz-se necessária a realização de novos estudos voltados para a avaliação de programas de saúde pública e do status imunológico das crianças vacinadas.

\section{REFERÊNCIAS}

1. Antunes FP, Costa MCN, Paim JS, Vieira- da -Silva LM, Cruz AA, Natividade M, et al. Desigualdades sociais na distribuição espacial das hospitalizações por doenças respiratórias. Cad Saude Publica. 2013;29(7):1346-56. https://doi.org/10.1590/S0102-311X2013000700009

2. Carneiro SMMV, Lessa SS, Guimarães JAL, Loepert MM, Silva DB. Cobertura vacinal real do esquema básico para o primeiro ano de vida numa Unidade de Saúde da Família. Rev Bras Med Fam Comunidade. 2012;7(23):100-7. https://doi.org/10.5712/rbmfc7(23)249

3. Carvalho CM, Madhi AS, O'Brien KL. Review of guidelines for evidence-based management for childhood community-acquired pneumonia in under- 5 tears from developed and developing countries. Pediatr Infect Dis J. 2013;32(11):1281-2. https://doi.org/10.1097/INF.0b013e3182a4dcfa

4. Cavalcanti SH, Caminha MFC, Figueiroa JN, Serva VMSBD, Cruz RSBLC, Lira PIC, et al. Factors associated with breastfeeding practice for at least six months in the state of Pernambuco, Brazil. Rev Bras Epidemiol. 2015;18(1):208-19. https://doi.org/10.1590/1980-5497201500010016

5. Chang AB, Ooi MH, Perera D, Grimwood K. Improving the diagnosis, management, and outcomes of children with pneumonia: where are the gaps? Front Pediatr. 2013;1:29. https://doi.org/10.3389/fped.2013.00029

6. Domingues CMAS, Teixeira AMS. Coberturas vacinais e doenças imunopreveníveis no Brasil no período 1982-2012: avanços e desafios do Programa Nacional de Imunizações. Epidemiol Serv Saude. 2013;22(1):9-27. https://doi.org/10.5123/S1679-49742013000100002

7. Dórea JG. Breast-feeding and responses to infant vaccines: constitutional and environmental factors. Am J Perinatol. 2012;29(10):759-75. https://doi.org/10.1055/s-0032-1316442

8. Edmond K, Scott S, Korczak V, Ward C, Sanderson C, Theodoratou E, et al. Long term sequelae from childhood pneumonia; systematic review and meta-analysis. PLoS One. 2012;7(2):e31239. https://doi.org/10.1371/journal.pone.0031239

9. Esposito S, Principi N. Unsolved problems in the approach to pediatric community-acquired pneumonia. Curr Opin Infect Dis. 2012;25(3):286-91. https://doi.org/10.1097/QCO.0b013e328352b60c

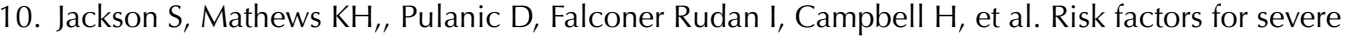
acute lower respiratory infections in children: a systematic review and meta-analysis. Croat Med J. 2013;54(2):110-21. https://doi.org/10.3325/cmj.2013.54.110 
11. Lantto $M$, Renko $M$, Uhari $M$. Changes in infectious disease mortality in children during the past three decades. Pediatr Infect. Dis J. 2013;32(9):e355-9. https://doi.org/10.1097/INF.0b013e3182930694

12. Levi GC. Recusa de vacinas: causas e consequências. São Paulo: Segmento Farma; 2013.

13. Lima EJF, Mello MJG, Albuquerque MFPM, Lopes MIL, Serra GHC, Abreu-Lima MAZS, et al. Clinical and epidemiological characteristics of severe community-acquired pneumonia in children after introduction of the 10-valent pneumococcal vaccine. Pediatric Health Med Ther. 2015;6:131-8. https://doi.org/10.2147/PHMT.S88132

14. Lima EJF, Lima DEP, Serra GHC, Lima MAZSA, Mello MJG. Prescription of antibiotics in community-acquired pneumonia in children: are we following the recommendations? Ther Clin Risk Manag. 2016;12:983-8. https://doi.org/10.2147/TCRM.S101709

15. Ministério da Saúde (BR), DATASUS. Cobertura vacinal por ano segundo imuno em Pernambuco. Brasília (DF); 2015 [citado 14 jul 2017]. Disponível em: http://tabnet.datasus.gov. br/cgi/tabcgi.exe?pni/CNV/CPNIPE.def

16. Ministério da Saúde (BR), Secretaria de Políticas de Saúde, Departamento de Atenção Básica. Saúde da criança: acompanhamento do crescimento e desenvolvimento. Brasília (DF): MS; 2002 [citado 14 jul 2017]. (Cadernos de Atenção Básica, 11); (Série A. Normas e Manuais Técnicos). Disponível em: http://bvsms.saude.gov.br/bvs/publicacoes/crescimento_desenvolvimento.pdf.

17. Ministério da Saúde (BR). SI-PNI - Sistema de Informação do Programa Nacional de Imunizações. Dados registrados por doses aplicadas. Brasília (DF): MS; 2012 [citado 14 jul 2017]. Disponível em: http://pni.datasus.gov.br/consulta_mrc_12_selecao.asp?naofechar=N\&env iar $=$ ok\&grupo=todos\&sel=dados_doses

18. Muenchhoff M, Goulder PJR. Sex diferences in pediatric infectious diseases. J Infect Dis. 2014;209 Suppl 3:S120-6. https://doi.org/10.1093/infdis/jiu232

19. Nascimento-Carvalho CM, Madhi SA, O'Brien KL. Is pneumonia among children in developing countries a different disease from the 1 among patients in the same age group in developed countries? Pediatric Infect Dis J. 2014;33(2):229-30. https://doi.org/10.1097/INF.0000000000000121

20. Rodrigues FE, Tatto RB, Vauchinski L, Leães LM, Rodrigues MM, Rodrigues VB, et al. Pneumonia mortality in Brazilian children younger than or equal to 4 years. J.Pediatr (Rio.J). 2011;87(2):111-4. https://doi.org/10.2223/JPED.2070

21. Silfverdal SA, Ekholm L, Bodin L. Breastfeeding enhances the antibody response to Hib and Pneumococcal serotype $6 \mathrm{~B}$ and 14 after vaccination with conjugate vaccines. Vaccine. 2007;25(8):1497-502. https://doi.org/10.1016/j.vaccine.2006.10.025

22. Sociedade Brasileira de Pediatria. Diretrizes brasileiras em pneumonia adquirida na comunidade em pediatria - 2007 pneumonias comunitárias. J Bras Pneumol. 2007;33 Supl 1:S31-50. https://doi.orb//10.1590/S1806-37132007000700002

23. Teixeira AMS, Rocha CMV. Vigilância das coberturas de vacinação: uma metodologia para detecção e intervenção em situação de risco. Epidemiol Serv Saude. 2010;19(3):217-26. https://doi.org/10.5123/S1679-49742010000300004

24. World Health Organization; UNICEF. Global action plan for prevention and control of pneumonia (GAPP). Geneva: WHO; 2009 [citado 14 jul 2017]. Disponível em: http://www. unicef.org/media/files/GAPP3_web.pdf

25. Williams DJ, Shah SS. Community-acquired pneumonia in the conjugate vaccine era. J Pediatric Infect Dis Soc. 2012;1(4):314-28. https://doi.org/10.1093/jpids/pis101

Contribuição dos Autores: Concepção, planejamento do estudo: ATPS, EJFL, MFCC, CSS. Coleta dos dados: ATPS, ATPS, EARF. Análise e interpretação dos dados: ATPS, EJFL, MFCC, CSS. Revisão crítica do manuscrito: ATPS, CSS, EJFL. Todos os autores aprovaram a versão final do manuscrito e assumem a responsabilidade pública pelo seu conteúdo.

Conflito de Interesses: Os autores declaram não haver conflito de interesses. 